\title{
Morphological and Functional Changes in the Thyroid Follicles of the Aged Murine and Humans
}

Junguee Lee · Shinae $\mathrm{Yi}^{1}$ Yea Eun Kang $\cdot$ Hyeon-Woo Kim ${ }^{1}$ Kyong Hye Joung ${ }^{1} \cdot$ Hae Joung Sul Koon Soon Kim ${ }^{1} \cdot$ Minho Shong ${ }^{1}$

Department of Pathology, Daejeon St. Mary's Hospital, College of Medicine, The Catholic University of Korea, Daejeon; 'Division of Endocrinology, Department of Internal Medicine, Research Center for Endocrine and Metabolic Diseases, Chungnam National University School of Medicine, Daejeon, Korea

Received: May 24, 2016

Revised: July 15, 2016

Accepted: July 19, 2016

Corresponding Author

Junguee Lee, MD, PhD

Department of Pathology,

Daejeon St. Mary's Hospital, College of Medicine,

The Catholic University of Korea, 64 Daeheung-ro,

Jung-gu, Daejeon 34943, Korea

Tel: $+82-42-220-9937$

Fax: $+82-42-252-9722$

E-mail: junguee@catholic.ac.kr
Background: Although both thyroid histology and serum concentrations of hormones are known to change with age, only a few reports exist on the relationship between the age-related structural and functional changes of the thyroid follicles in both mice and humans. Our objectives were to investigate age-related histological changes of the thyroid follicles and to determine whether these morphological changes were associated with the functional activity of the follicles. Methods: The thyroid glands of mice at 18 weeks and at 6,15 , and 30 months of age were histologically examined, and the serum levels of thyroid hormones were measured in 11-week-old and 20-month-old mice. Samples of human thyroid tissue from 10 women over 70 years old and 10 women between 30 and 50 years of age were analyzed in conjunction with serum thyroid hormone level. Results: The histological and functional changes observed in the thyroid follicles of aged mice and women were as follows: variable sizing and enlargement of the follicles; increased irregularity of follicles; Sanderson's polsters in the wall of large follicles; a large thyroglobulin $(\mathrm{Tg})$ globule or numerous small fragmented Tg globules in follicular lumens; oncocytic change in follicular cells; and markedly dilated follicles empty of colloid. Serum T3 levels in 20-month-old mice and humans were unremarkable. Conclusions: Thyroid follicles of aged mice and women show characteristic morphological changes, such as cystic atrophy, empty colloid, and Tg globules.

Key Words: Aged; Elderly; Thyroid gland; Thyroid hormones
The functional unit of the thyroid gland is the thyroid follicle, which is composed of follicular cells and intrafollicular colloid. The size and shape of thyroid follicles and the height of the follicular epithelium vary depending on the thyroid's functional activity. In addition, there is morphological heterogeneity of the intrafollicular colloid depending on the thyroid's functional status. ${ }^{1}$

Aging induces morphological and functional changes in the thyroid and leads to gradual loss of the ability to maintain homeostasis. Increases in size and number of follicles have been reported in the aged male albino rat and in the humped camel; ${ }^{2}$ however, the thyroid of a human over the age of 60 undergoes progressive fibrosis and atrophy, leading to a reduction in thyroid volume. ${ }^{3,4}$ The loss of follicular cells due to age-associated cell death has been reported, but the loss of thyroid function is debated.

Most pronounced age-related changes occur in nondividing and infrequently dividing cells that have longer turnover times, such as brain (turnover time of neurons, about 16,425 days), muscle (turnover time of myocyte, about 5,510 days), and liver (turnover time of hepatocyte, about 327 days). Longer cell turnover time allows for a greater accumulation of DNA damage with age. Cells that accumulate DNA damage may have reduced viability and loss of function, which eventually lead to tissue atrophy. Human thyroid follicular cells have a longer turnover time (about 3,180 days) than cells of other endocrine organs, such as the adrenal gland (about 455 days) and pancreas (about 265 days). ${ }^{5}$

Although there are some studies on age-related histological changes of the thyroid gland, there are few on the relationship between histological changes and functional activity of aged thyroid follicles. The present study examines age-related structural and functional changes in the thyroid follicles and investigates the impact of these changes on serum thyroid hormone concentrations. 


\section{MATERIALS AND METHODS}

\section{Animals and tissue histology}

Thyroids were excised from C57BL/6 male mice that were sacrificed at 18 weeks $(n=2), 6$ months $(n=2), 15$ months ( $\mathrm{n}=$ 2 ), or 30 months ( $\mathrm{n}=2)$ of age. The mice had been fed a normal chow diet since birth and were maintained in accordance with the principles of laboratory animal care. For analysis, they were grouped as follows: control mice (18 weeks old), adult mice (six months old), and aged mice (15 and 30 months old). Blood was collected from the retro-orbital sinus in anesthetized 11-weekold ( $\mathrm{n}=7$ ) or 20-month-old ( $\mathrm{n}=7$ ) C57BL/6 male mice in order to measure serum thyroid hormone levels. The mice were subsequently sacrificed.

Each thyroid was fixed in $10 \%$ neutral buffered formalin and paraffin-embedded in the transverse plane using standard procedures. Paraffin-embedded tissue sections (4- $\mu$ m-thick) were stained with hematoxylin and eosin (H\&E) for histological analysis, which included follicle size and shape, follicular cell height, and characteristics of the cytoplasm and intrafollicular colloid.

Tissue sections were stained with periodic-acid-Schiff (PAS), which stains the glycoprotein thyroglobulin $(\mathrm{Tg})$ in the colloid purple-red. The PAS stain intensity of the intrafollicular colloid was then compared between samples. In hypoactive follicles, $\mathrm{Tg}$ accumulates in the colloid and stains dark blue-purple with PAS.

All mouse experiments were approved by the university committee for animal experiments and were performed in accordance with the National Research Council Guide for the Care and Use of Laboratory Animals and in accordance with the Guidelines for the Care and Use of Laboratory Animals prepared by the Institute for Laboratory Animal Research, National Academy of Sciences.

\section{Measurements of thyroid hormone}

Retro-orbitally collected, clotted mouse blood was centrifuged at 3,000 $\times \mathrm{g}$ for 10 minutes. Sera were separated and stored at $-20^{\circ} \mathrm{C}$ prior to the hormonal assay. Total T3 and T4 levels were measured using an enzyme-linked immunosorbent assay kit (Merck Millipore, Darmstadt, Germany) according to the manufacturer's instructions. Serum thyroid-stimulating hormone (TSH) was measured using a specific mouse TSH radioimmunoassay provided by Dr. Cheng S.Y. (Center for Cancer Research, National Cancer Institute, Bethesda, MD, USA).

\section{Analysis of size and shape of thyroid follicles}

Sections of the whole thyroid gland (approximately 20 serial sections) at $\times 100$ magnification were used to assess the area of the follicles. The inner area of the thyroid gland at half the maximum length in the longitudinal planes was considered the central zone, and the area surrounding the central zone was considered the peripheral zone (Fig. 1A, left). The same approach was taken in the transverse planes of the thyroid gland (Fig. 1A, right). The size of the follicles in the central zone was compared with the size of the follicles in the peripheral zone.

Follicles that were neither ovoid/round nor smooth in outline were considered to be of irregular shape. Irregularly-shaped follicles were assessed in 20 serial sections using $\times 100$ magnification images of the whole thyroid gland section.
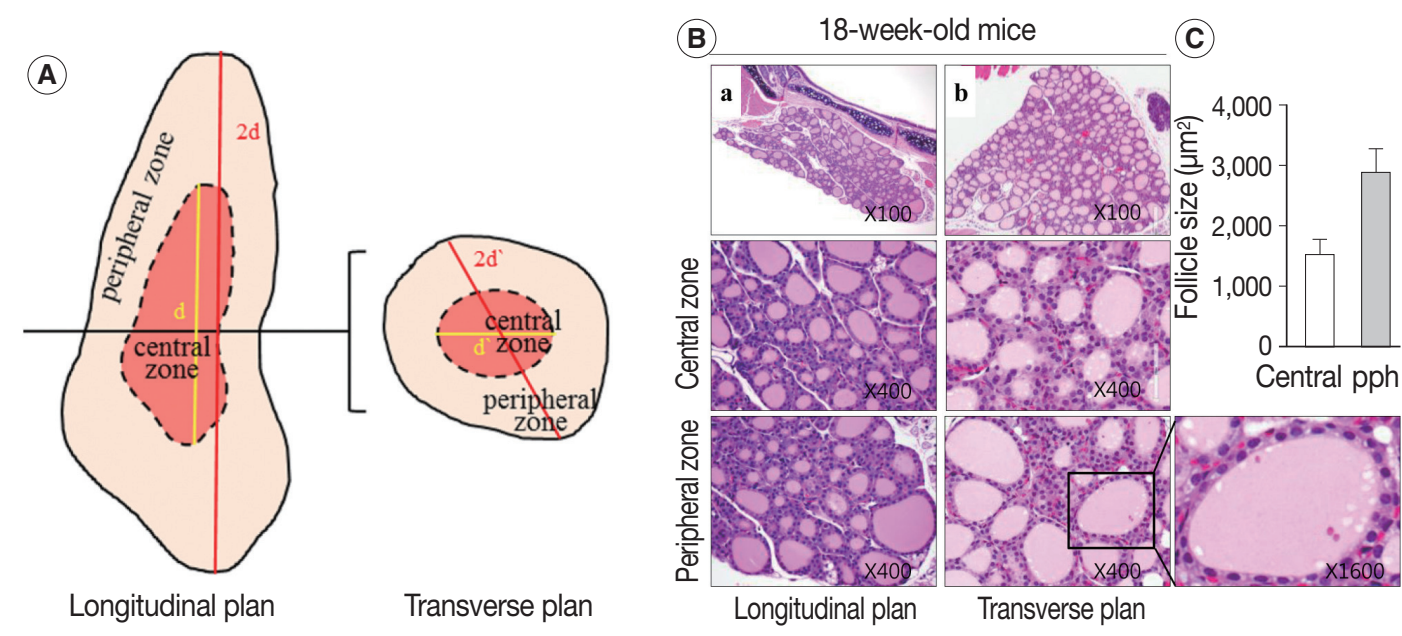

Fig. 1. The 18-week-old control thyroid gland. (A) Description of the central and peripheral zones of the thyroid gland in the longitudinal and transverse planes. $(\mathrm{B}, \mathrm{C})$ Conserved zonal variation in the thyroids of 18-week-old control mice. (B) Hematoxylin and eosin-stained sections of thyroid from an 18-week-old control mouse in the central and peripheral zones. (C) Mean area ( \pm standard deviation, $n=2)$ of follicles in the central and peripheral (pph) zones of an 18-week-old mouse thyroid. 


\section{Immunohistochemistry analysis}

To assess mitochondrial content, tissue sections were immunostained with an antibody against the translocase of the outer mitochondrial membrane (TOM20). Paraffin-embedded tissue sections (4- $\mu \mathrm{m}$-thick) were placed in an oven and incubated at $56^{\circ} \mathrm{C}$ for three hours before immunohistochemistry. Specimens were stained using the Ventana HX automatic system from BenchMark (Ventana Medical Systems, SA, Illkirch Cedex, France) with an anti-TOM20 rabbit polyclonal antibody (Santa Cruz Biotechnology, Santa Cruz, CA, USA). All procedures, including antigen retrieval and blocking of endogenous peroxidase activity, were performed automatically by the BenchMark system. The tissue sections were incubated with primary antibody for 32 minutes at $42^{\circ} \mathrm{C}$. Immunoperoxidase staining was performed using the LSAB NeuVision system, according to the manufacturer's instructions (Ventana Medical Systems), and sections were counterstained with hematoxylin. Tissue slides were analyzed using an OLYMPUS BX51 microscope (Olympus, Tokyo, Japan).

The immunoreactivities of TOM20 were analyzed for all cases. The intensity of TOM20 immunoexpression was scored as follows: 0 , negative; 1 , weakly positive; 2 , moderately positive; and 3, strongly positive.

\section{Human tissue histology and clinical data}

H\&E-stained, paraffin-embedded thyroid tissue and thyroid function test results (serum concentrations of TSH, T3, and T4) from 10 women over the age of 70 and 10 women between 30 and 50 years of age who underwent total thyroidectomy between January 2002 and December 2005 at Daejeon St. Mary's Hospital, Daejeon, Korea, were analyzed retrospectively. All patients presented with papillary thyroid carcinoma (PTC). Normal thyroid tissues of the contralateral lobe of PTC were analyzed for agerelated change. The study protocol was reviewed and approved by the Institutional Review Board of Daejeon St. Mary's Hospital, College of Medicine, The Catholic University of Korea. All participants provided signed, written informed consent. All experiments were performed in accordance with relevant guidelines and regulations. The baseline characteristics and thyroid function test results of each human participant are summarized in Table 1.

\section{Statistical analysis}

Group comparisons of categorical variables were evaluated using a linear-by-linear association. The means were compared

Table 1. Summary of human characteristics and thyroid function tests

\begin{tabular}{|c|c|c|c|}
\hline Age (yr) & Serum T3 (nmol/L) & Serum T4 ( $\mu \mathrm{g} / \mathrm{dL})$ & TSH (ulU/mL) \\
\hline \multicolumn{4}{|c|}{ 30-50-year-old women } \\
\hline 36 & 1.3 & 8.5 & 1.42 \\
\hline 39 & 1.1 & 7.63 & 1.53 \\
\hline 44 & 1.0 & 8.2 & 2.03 \\
\hline 45 & 1.07 & 9.08 & 2.53 \\
\hline 46 & 1.2 & 12.1 & 2.67 \\
\hline 46 & 1.0 & 7.8 & 2.57 \\
\hline 46 & 1.0 & 9.5 & 2.6 \\
\hline 47 & 1.1 & 6.1 & 5.28 \\
\hline 47 & 1.1 & 6.35 & 3.48 \\
\hline 50 & 1.0 & 8.6 & 1.15 \\
\hline Mean $\pm S D$ & $1.087 \pm 0.096$ & $8.386 \pm 1.696$ & $2.526 \pm 1.196$ \\
\hline \multicolumn{4}{|c|}{ > 70-year-old women } \\
\hline 71 & 1.4 & 7.3 & 0.32 \\
\hline 73 & 1.2 & 4 & 2.37 \\
\hline 74 & 1.9 & 7.76 & 0.01 \\
\hline 75 & 1.3 & 7.3 & 3.83 \\
\hline 75 & 1.38 & 7.3 & 1.74 \\
\hline 77 & 1.61 & 7.3 & 1.9 \\
\hline 77 & 1.2 & 8.8 & 2.54 \\
\hline 77 & 1.1 & 8.4 & 0.16 \\
\hline 78 & 1.09 & 7.3 & 0.75 \\
\hline Mean \pm SD & $1.348 \pm 0.248$ & $7.296 \pm 1.274$ & $1.648 \pm 1.295$ \\
\hline
\end{tabular}

Normal range: TSH, 0.27-4.2 ulU/mL; serum T3, 1.3-3.1 nmol/L; serum T4, 5.4-11.5 $\mu \mathrm{g} / \mathrm{dL}$.

T3, triiodothyronine; T4, thyroxine; TSH, thyroid stimulating hormone; SD, standard deviation. 
with the result of the independent sample t-test. Values are represented as the mean \pm SEM. A p-value less than .05 was considered statistically significant. Analyses were performed using SPSS ver. 22.0 statistical software (IBM Corp., Armonk, NY, USA).

\section{RESULTS}

\section{Serum thyroid hormone concentrations and thyroid functional activity in aged mice}

We measured serum levels of TSH, T3, and T4 in 20-monthold mice (aged group; $\mathrm{n}=7$ ) and compared them with levels of the same hormones in 11-week-old mice (control group; $\mathrm{n}=7$ ) (Table 2). Serum T3 concentrations were lower in the aged group than in the control group, but there was no difference in serum T4 and serum TSH levels between the two groups.

The thyroid activation index, expressed as the ratio of follicular cell volume to colloid volume, reflects changes in thyroid function caused by alterations in TSH level., ${ }^{6,7}$ Thyroid tissue from 18-week-old control mice was composed of a relatively homogeneous population of small- to medium-sized round follicles lined with cuboidal epithelium (Fig. 1B). In contrast, the 30-monthold mouse thyroid was composed of dilated or irregularly-shaped follicles (Fig. 2E), and the dilated follicles were lined with flat epithelium. The intrafollicular colloid volume was larger in 30-month-old mice than in the controls. Consequently, the younger thyroid, which was composed of cuboidal or columnar epithelium and a small amount of colloid, had a higher thyroid activation index than the older thyroid, which was composed of a flat epithelium and significantly more colloid.

\section{Irregularly enlarged thyroid follicles in aged mice}

Next, we examined whether the histological changes in the thyroid follicles of aged mice correlated with thyroid function. The 18-week-old control thyroid glands were composed of smallto medium-sized round follicles. The larger follicles tended to localize in the peripheral region of the thyroid gland. These distributions of follicles is called the zonal variations in follicle size. ${ }^{8,9}$ Zonal variation in the size of thyroid follicles was well preserved. Thyroid follicles of the central zone were smaller than those of the peripheral zone, with a ratio of the area of central zone to peripheral zone follicles of 1:2 (Fig. 1B, C). The adult mouse thyroid gland (6 months old) was composed of variable-sized follicles with a relatively round shape. The zonal variation in the size of thyroid follicles was well preserved; however, follicles in the peripheral zone were three times larger than those in the central zone (Fig. 2A, B). Smaller follicles found in the central zone were lined with a cuboidal epithelium, and larger follicles located in the peripheral zone were lined with a cuboidal or low cuboidal epithelium (Fig. 2A). Thyroid glands from aged mice (15 months old and 30 months old) were composed of irregularly dilated follicles, which were considered to be inactive (Fig. 2C, E). There was a greater incidence of inactive large follicles in the aged mice compared to the thyroid of adult mice. Zonal variation in the size of thyroid follicles was not conserved (Fig. 2D, F). Dilated follicles were not only present in the periphery of the gland, but were also seen in the central zone. The aged thyroids were extremely heterogeneous in appearance, exhibiting variability in the height of the follicular epithelium and in the amount of intrafollicular colloid. Furthermore, papillary and glandular proliferations were observed in the epithelium (Fig. 3A, B). Irregularly-shaped follicles were also observed in aged mouse thyroid glands. This was more frequently observed in the 30-month than in the 15-month-old mice (Fig. 3A, B). Most irregularly-shaped follicles were surrounded by a cuboidal or high cuboidal epithelium.

In the thyroid glands of aged mice, some of the large dilated follicles had cellular areas composed of small follicles lined by a crowded epithelium with scant colloid in a small lumen; these were pushing into large colloid-filled follicles. This characteristic lesion is referred to as a Sanderson's polster (Fig. 3A, B). Some of the large dilated follicles also had asymmetric pseudopapillary

Table 2. Mouse thyroid function tests

\begin{tabular}{|c|c|c|c|c|c|c|}
\hline \multirow{2}{*}{ No. } & \multicolumn{3}{|c|}{ 11-week-old mice } & \multicolumn{3}{|c|}{ 20-month-old mice } \\
\hline & Serum T3 (ng/mL) & Serum T4 ( $\mu \mathrm{g} / \mathrm{dL})$ & TSH (ng/mL) & Serum T3 (ng/mL) & Serum T4 ( $\mu \mathrm{g} / \mathrm{dL})$ & TSH (ng/mL) \\
\hline 1 & 0.77 & 4.33 & 139.36 & 0.23 & 3.84 & 29.45 \\
\hline 3 & 0.71 & 4.49 & 82.22 & 0.09 & 3.35 & 135.39 \\
\hline 4 & 0.90 & 4.07 & 155.40 & 0.13 & 3.85 & 56.85 \\
\hline 5 & 0.91 & 4.53 & 50.75 & 0.25 & 4.46 & 93.22 \\
\hline 6 & 0.66 & 3.77 & 82.07 & 0.12 & 5.40 & 73.80 \\
\hline 7 & 0.55 & 3.48 & 79.56 & 0.33 & 5.41 & 52.10 \\
\hline Mean \pm SD & $0.766 \pm 0.116$ & $4.026 \pm 0.386$ & $94.52 \pm 32.897$ & $0.187 \pm 0.074$ & $4.287 \pm 0.719$ & $68.617 \pm 31.391$ \\
\hline
\end{tabular}

T3, triiodothyronine; T4, thyroxine; TSH, thyroid stimulating hormone; SD, standard deviation. 


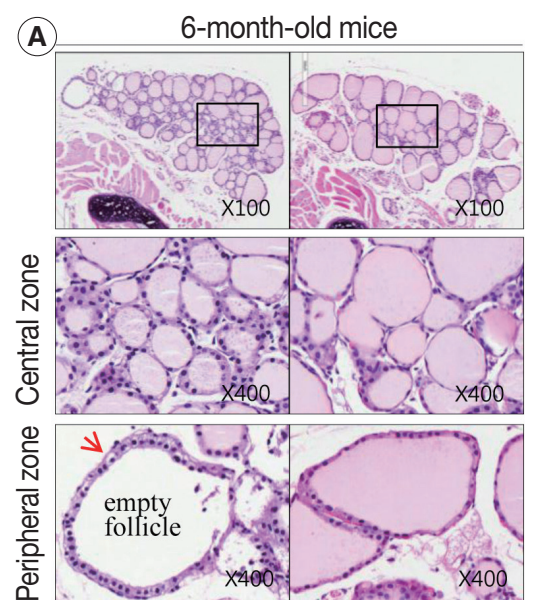

(a)

(b)

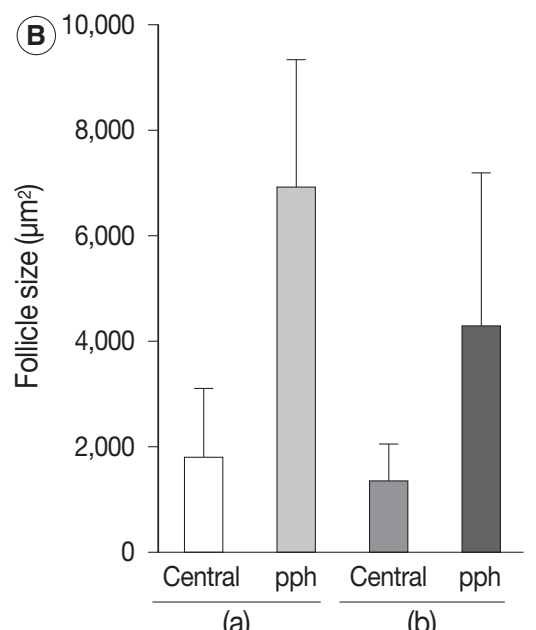

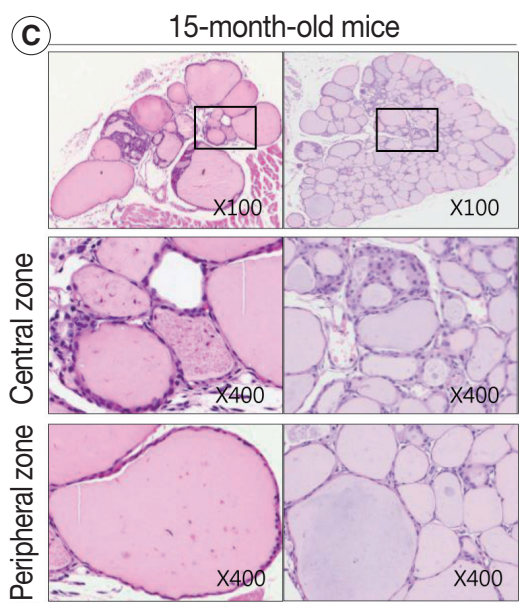

(a)

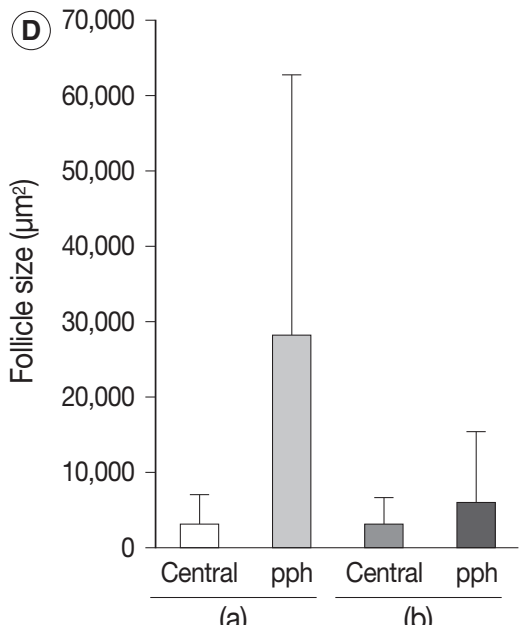

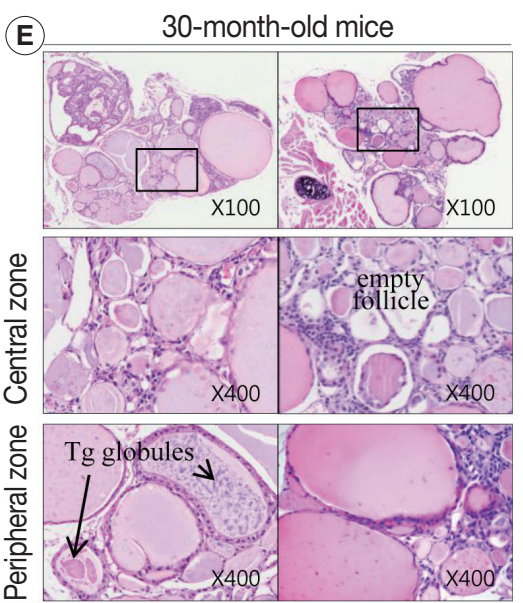

(a)

(b)

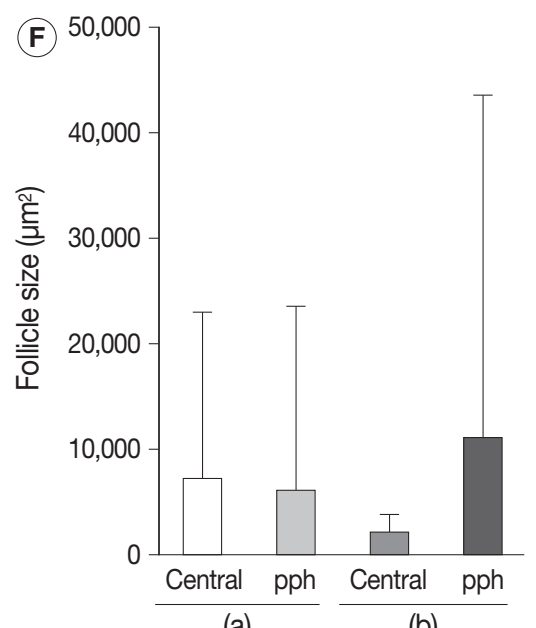

Fig. 2. Adult and aged mouse thyroid gland. (A-F) Markedly enlarged follicles and loss of zonal variation in follicle size in aged mice. (A, C, E) Hematoxylin and eosin-stained sections of thyroid from 6-month-old (A), 15-month-old (C), and 30-month-old (E) mice in the central and peripheral zones. (B, D, F) Mean area ( \pm standard deviation; $n=2$ ) of follicles in the central and peripheral (pph) zones. Tg, thyroglobulin.

projections of crowded columnar cells (Fig. 3B).

\section{Tg globules in the follicular lumen of aged mice}

Intrafollicular colloid of control and adult thyroids stained homogeneously pink by $\mathrm{H} \& \mathrm{E}$ (Figs. 1B, 2A). In the control group, many endocytic vacuoles were seen near the margin of the colloid-filled lumen (Fig. 1B, arrow). These vacuoles emerge with dissolution of colloid by acid phosphatase that is secreted from lysosomes in conjunction with hormonal release during follicular cell activity. ${ }^{10}$ Thus, colloid endocytosis correlates with follicular cell activity. In 6-month-old adult thyroids, several follicles in the peripheral zone were empty and were lined with a high cuboidal epithelium. The follicular cells of the empty follicles had clear cytoplasm and a centrally located, shrunken nucleus (Fig. 2A, arrow). These clear cell changes were suggestive of a distended endoplasmic reticulum, which was interpreted as a sign of follicular degeneration. Colloid vacuolation was frequently observed in the adult thyroid.

In the aged thyroid (15 months old and 30 months old), colloid-filled follicles lined with a flat epithelium stained homogeneously pink with $\mathrm{H} \& \mathrm{E}$, while colloid within the follicles lined with a high cuboidal epithelium was pale and coarsely granular (Fig. 2C, E). There were numerous small, fragmented, and clumped $\mathrm{Tg}$ globules within the intrafollicular colloid that were surrounded by a high cuboidal or oncocytic epithelium (Figs. 2E, 3B). The formation of $\mathrm{Tg}$ multimers allows for storage of $\mathrm{Tg}$ at excessively high concentrations, and they are more frequently observed in hypofunctioning follicles. ${ }^{1,11}$ Some of the thyroid follicles were empty, and others contained only small amounts of colloid in their larger lumen (Fig. 2E). Empty follicles are inactive 
(A)
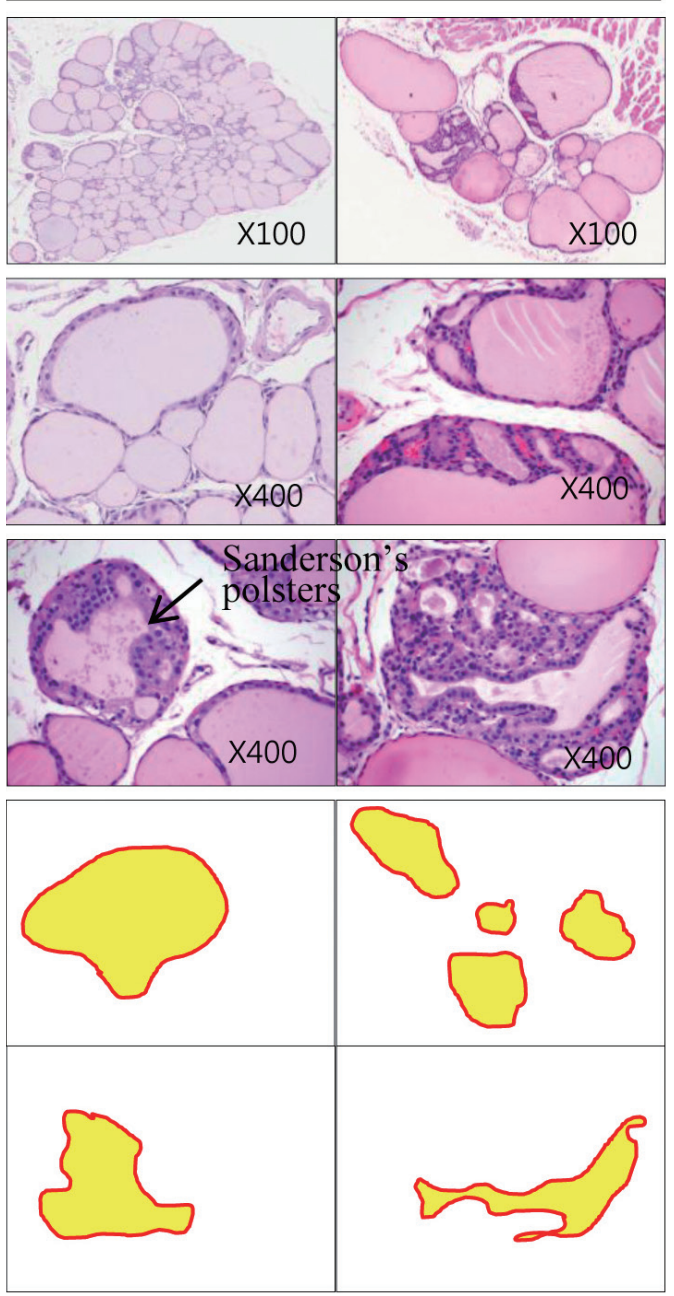

(C)
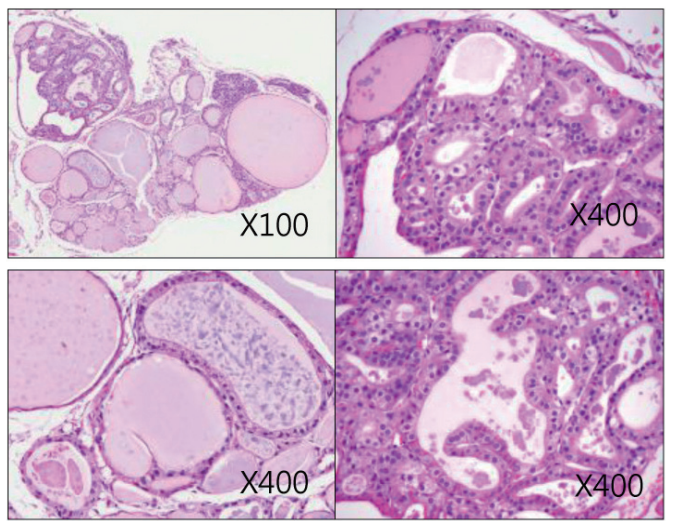

(B)

30-month-old mice
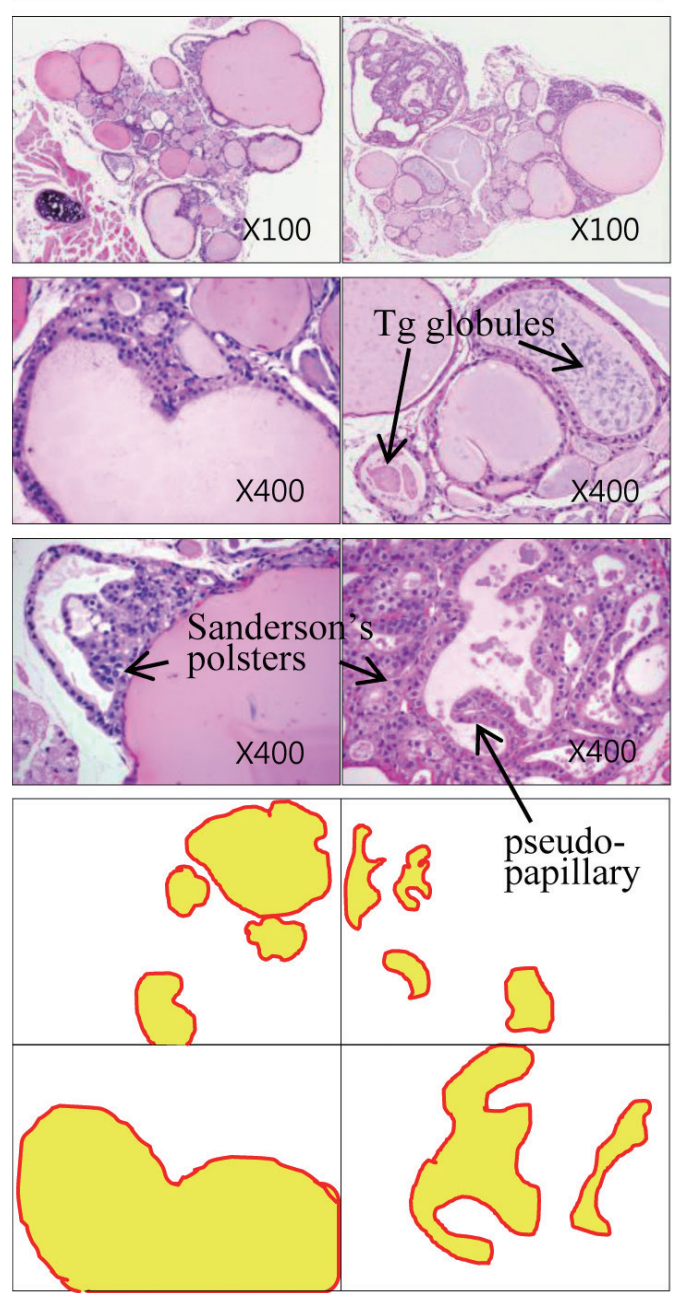

(D)

TOM20
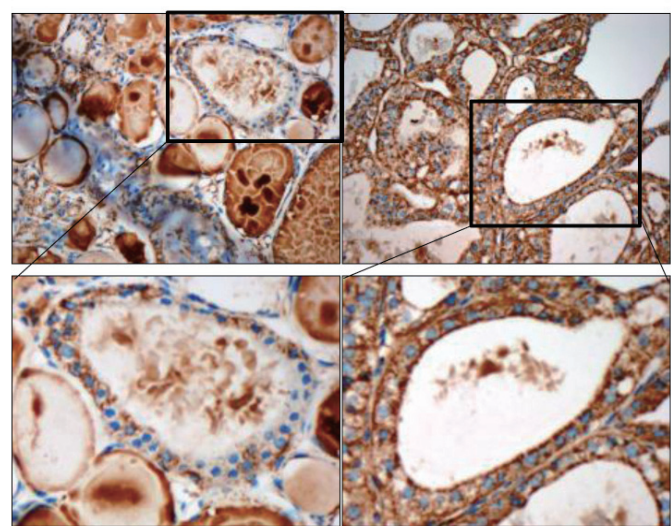

(a)

Fig. 3. Increased irregularity of follicles in the aged mouse thyroid. Hematoxylin and eosin (H\&E)-stained sections of thyroid from 15-monthold (A) and 30-month-old (B) mice. (C) Oncocytic change in the follicular cells of aged mouse thyroid stained with H\&E. (D) Sections of 30-month-old mouse thyroid stained with anti-translocase of the outer mitochondrial membrane (TOM20) antibody visualized by 3,3'-diaminobenzidine. Non-oncocytic follicular cells are weak for TOM20 (left panels), while oncocytic follicular cells are strongly TOM20-positive (right panels). Tg, thyroglobulin. 
follicles that may have lost accumulated colloid over time due to stasis of colloid circulation. Colloid vacuolation, which signifies colloid resorption, was occasionally observed. Briefly, these findings indicated decreased thyroid gland activity with increasing age.

\section{Oncocytic change in thyroid follicular cells in aged mice}

In 30-month-old mouse thyroids, follicles lined with a low columnar epithelium showed oncocytic changes that were characterized by an abundant oxyphilic, granular cytoplasm and a large hyperchromatic nucleus (Fig. 3C). An oncocytic appearance is the result of mitochondrial proliferation, which is a mechanism to compensate for mitochondrial defects. Compared with nononcocytic follicular cells, oncocytic follicular cells were intensely stained by the TOM20 antibody. The TOM20 score was 1 and 3 in non-oncocytic follicular cells and oncocytic follicular cells, respectively (Fig. 3D).

\section{Colloid densities in follicular lumens}

After analyzing the intensity and multimerization of PASstained intrafollicular colloid, we compared intrafollicular colloid concentrations and follicular activity for each age group. Fig. 4 shows the PAS-positive density of the colloid in each group.

Regular thyroid follicles of the adult group (6 months old) were filled with homogeneously PAS-positive colloid. PASpositive colloid in the peripheral zone was more darkly stained than the PAS-positive colloid in the central zone. Few follicles exhibited PAS-negative lumens (Fig. 4A).

The markedly enlarged follicles of the aged group (15 months old and 30 months old) had an increased PAS-positive density (dark blue-purple PAS stain) (Fig. 4C). The colloid in irregularlyshaped follicles and in small follicles was stained purple-red by PAS. Sanderson's polsters were observed on one side of the large, dilated follicles. These aggregated, small follicles are composed of a high cuboidal epithelium and lead to depletion of luminal colloid. Sanderson's polsters were heterogeneously stained by PAS. Abundant colloid in large follicles was stained purple-red or dark blue-purple by PAS, while cellular areas composed of small follicles were pale-red or negative (Fig. 4C). Thus, the markedly enlarged follicles seen in aged mice were considered to be hypoactive compared with small follicles, irregularlyshaped follicles, and Sanderson's polsters.

\section{Thyroid histology and thyroid function tests in elderly women}

We also analyzed age-related histological changes in the thyroid glands of 10 women over 70 years of age and compared them
(A)
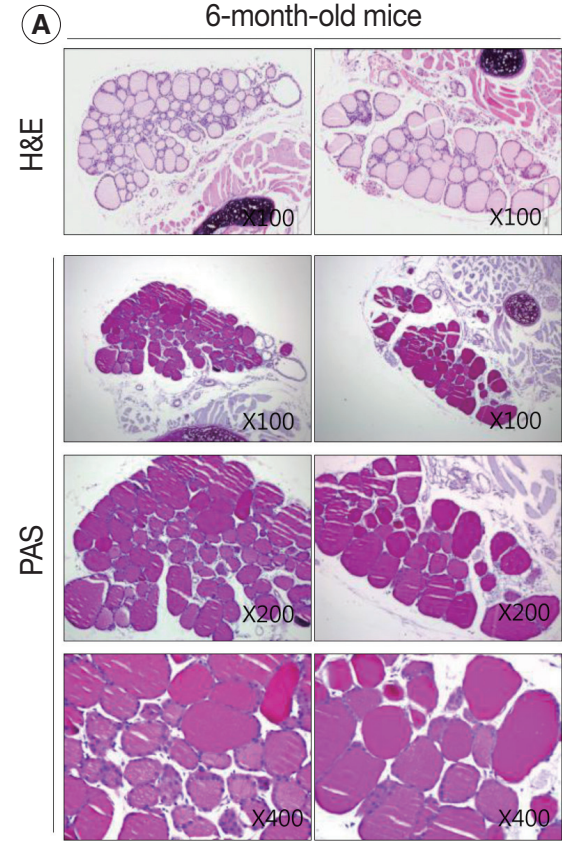

B 15-month-old mice
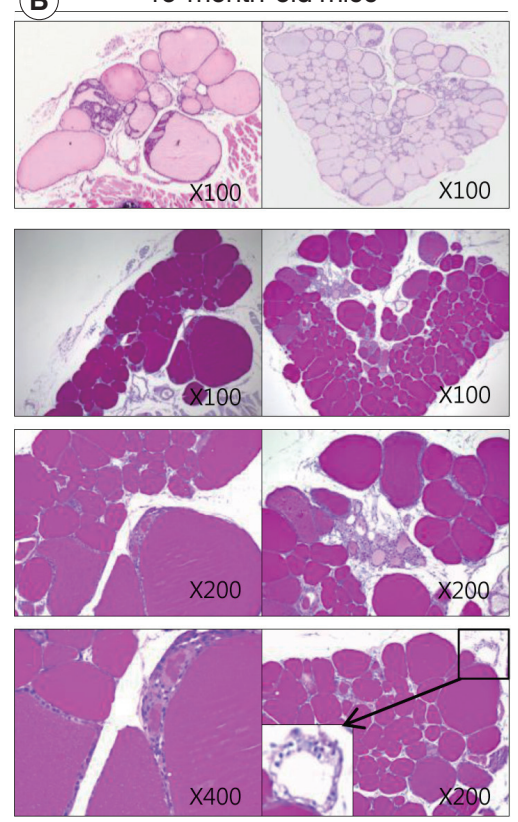
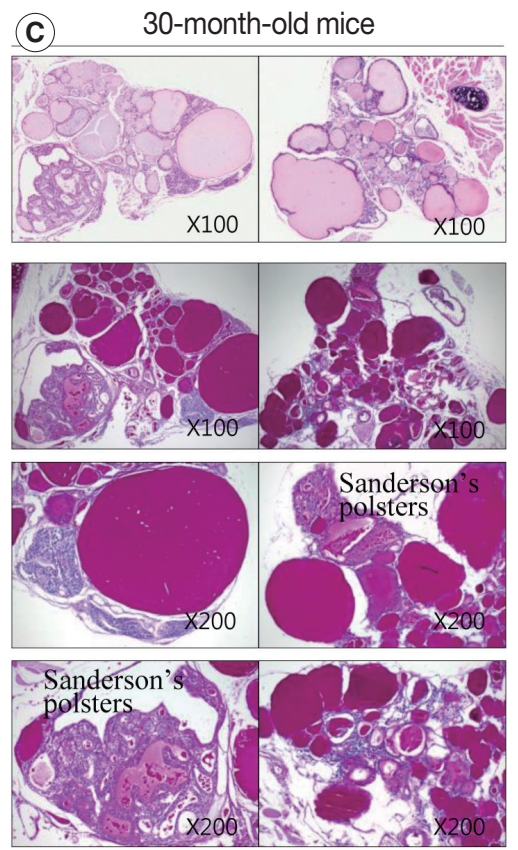

Fig. 4. Colloid density in thyroid follicular lumens. (A-C) The density of periodic-acid-Schiff (PAS)-positive intrafollicular colloid in each age group. Sections of 6-month-old (A), 15-month-old (B), and 30-month-old (C) mice thyroids stained with hematoxylin and eosin (H\&E) (top row) and PAS at the indicated magnifications. The markedly enlarged follicles in the aged thyroids $(B, C)$ exhibit increased PAS-positive colloid density. The PAS-positive density of the colloid in irregularly-shaped and empty follicles is significantly decreased compared to the adult group (A). Follicles in the peripheral zones of 15-month-old mice are empty with clear cytoplasm and a centrally located shrunken nucleus (B, inset). 
with thyroids from women between 30 and 50 years of age. We observed findings similar to those seen in aged mice, including (1) variable size and enlargement of follicles (Fig. 5A); (2) increased irregularity of the follicles (Fig. 5B); (3) Sanderson's polsters in the walls of large follicles (Fig. 5B); (4) a large Tg globule or numerous, small, fragmented Tg globules in the follicular lumen (Fig. 5C);
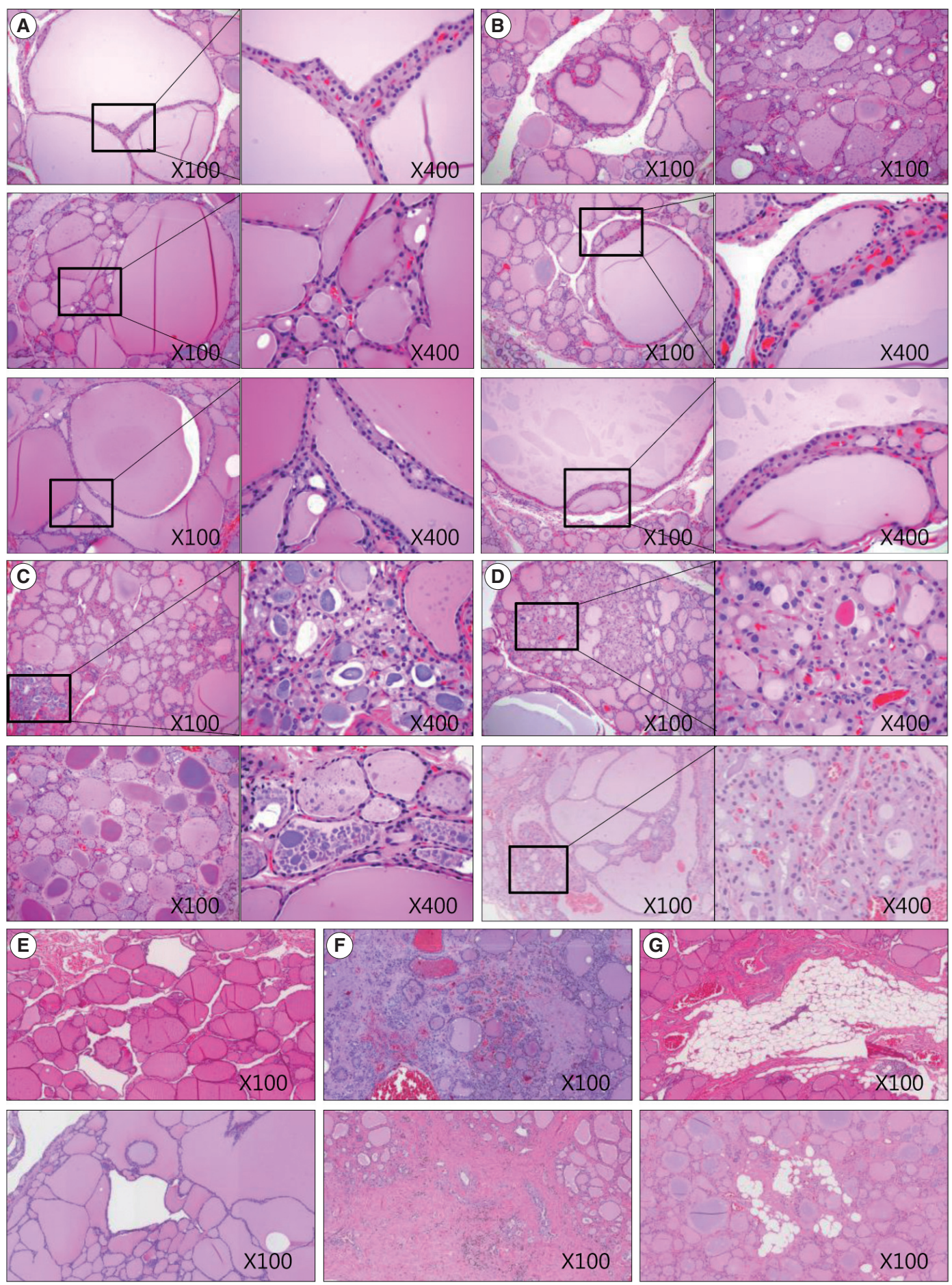

Fig. 5. Sections of thyroid from elderly females highlighting various morphological changes. (A) Size variation and enlargement of the follicles. (B) Increased irregularity of follicles and Sanderson's polsters in the wall of large follicles. (C) A large thyroglobulin (Tg) globule (right upper image) and numerous small fragmented Tg globules (right lower image) in the follicular lumen. (D) Oncocytic change in the follicular cells and in those with Sanderson's polsters. (E) Irregularly dilated follicles lacking colloid. (F) Fibrosis of the extracellular matrix. (G) Fatty infiltration in the extracellular matrix. 
(5) oncocytic change in the follicular cells (Fig. 5D); and (6) markedly dilated follicles lacking colloid (Fig. 5E). However, unlike the thyroids of aged mice, fibrosis or fatty infiltration within the extracellular matrix was observed in elderly human thyroids (Fig. 5F, G).

Among the 10 elderly women, thyroid hormone levels were unremarkable when compared with controls ( $\mathrm{T} 3, \mathrm{p}=.551$; $\mathrm{T} 4$, $\mathrm{p}=.138 ;$ TSH, $\mathrm{p}=.085)$ (Table 1). Age-related histological changes and functional activities in the human thyroid follicles were not associated with changes in serum thyroid hormone levels.

\section{DISCUSSION}

In this study, we identified age-related histological changes in the thyroid glands of aged mice. These changes included a decrease in the entire thyroid size, formation of markedly dilated follicles with a flat epithelium, irregularly-shaped follicles, aggregations of small follicles with oncocytic epithelia, the presence of colloid-depleted follicles, a large $\mathrm{Tg}$ globule or multimeric $\mathrm{Tg}$ globules within the colloid, and loss of zonal variation. Fibrosis, inflammation, and fatty infiltration were common in elderly human thyroids but rarely observed in aged mouse thyroids. Of these changes, the height of the follicular epithelium, cytoplasmic features of follicular cells, PAS staining properties of the colloid, and characteristic $\mathrm{Tg}$ globules are representative of functional activity of the thyroid follicles. A commonly encountered pattern in the aged mice thyroid was prominent cystically dilated follicles with flimsy walls composed of scant fibrous stroma. We attributed this characteristic histological finding to cystic atrophy of the follicle. Cystic atrophy is not infrequently found in the postmenopausal endometrium. In the absence of ovarian function, the endometrium experiences cystic atrophy, having a thin uterine mucosa, cystically dilated endometrial glands, and a flattened inactive epithelium. ${ }^{12}$ The pathogenesis of cystic atrophy of the endometrium has not yet been established. In cystic atrophy of the aged thyroid, low cuboidal or flattened and inactive follicular cells line the distended follicles. Larger or dilated follicles lined with a low cuboidal epithelium contain colloid that stains purplered with PAS, while larger or dilated follicles with a flat epithelium contain thick colloid that stains dark blue-purple with PAS. As organisms get older, the function of thyroid follicular cells tends to diminish, thus decreasing endocytosis of luminal colloid into follicular cells. Eventually, the accumulation of luminal colloid increases intrafollicular pressure and increases tension in the follicular wall, which may contribute to the flattening of follicular cells. $^{13}$

Oncocytic change in cells is increasingly observed with advancing age in thyroid glands and in other organs. ${ }^{14}$ In the involuted thyroids of old mice, a follicular epithelium with oncocytic change is more frequently observed. The characteristic oncocytic appearance, which consists of an abundant oxyphilic, granular cytoplasm and a large hyperchromatic nucleus, is the result of mitochondrial proliferation that compensates for mitochondrial defects. ${ }^{15}$ Mitochondrial function is very important for maintaining functional activity in most endocrine organs; therefore, age-related changes in the mitochondria are likely to impair endocrine organ function. Colloid changes were apparent in 15-month-old and 30-month-old mice. Intrafollicular colloid took on the appearance of a large Tg globule or of numerous, small, fragmented $\mathrm{Tg}$ globules within oncocytic follicles. A large globule or multimeric $\mathrm{Tg}$ globules are more frequently present in hypofunctioning follicles than in active follicles. ${ }^{1}$ In aged mice, we observed oncocytic follicular epithelia lining lumens lacking colloid, which is a characteristic sign of an inactive follicle. We found that follicles composed of oncocytic epithelia are more likely to be irregular in shape, lack colloid, or have highly insoluble colloid. These results demonstrate the important role of mitochondrial function in maintaining proper activity of the thyroid follicular cell.

With advancing age, conversion of functional tissue to fatty or fibrous tissue occurs in most organs, and fundamental tissue loss in a variety of organs is associated with a decrease in proper function. In the aged mouse, however, there is a paucity of conversion to fatty or fibrous tissue. Instead, cystic atrophy is common. Although conversion of thyroid follicles to fatty or fibrous tissue is occasionally observed in elderly women, the proportion of fatty or fibrous tissue within thyroid is not so pronounced.

In conclusion, follicular cells and the follicles of aged thyroids show characteristic morphological changes, which include cystic atrophy, empty colloid, Tg globules, and oncocytic follicular cells.

\section{Conflicts of Interest}

No potential conflict of interest relevant to this article was reported.

\section{Acknowledgments}

This work was supported by The Catholic University of Korea Daejeon St. Mary's Hospital, and by a clinical research institute grant funded by The Catholic University of Korea Daejeon St. Mary's Hospital (CMCDJ-A-2015-003). MS was supported by a research grant from Chungnam National University. 


\section{REFERENCES}

1. Gerard AC, Denef JF, Colin IM, van den Hove MF. Evidence for processing of compact insoluble thyroglobulin globules in relation with follicular cell functional activity in the human and the mouse thyroid. Eur J Endocrinol 2004; 150: 73-80.

2. El-Desouki NI, Afifi DF, El-Refaiy AI, Talaat H. Age-related changes in histological and cytoskeletal intermediate filaments of rabbits thyroid glands and the prophylactic role of vitamin E. Glob Vet 2014; 13: 511-519.

3. Rao-Rupanagudi S, Heywood R, Gopinath C. Age-related changes in thyroid structure and function in Sprague-Dawley rats. Vet Pathol 1992; 29: 278-87.

4. Ajish TP, Jayakumar RV. Geriatric thyroidology: an update. Indian J Endocrinol Metab 2012; 16: 542-7.

5. Coclet J, Foureau F, Ketelbant P, Galand P, Dumont JE. Cell population kinetics in dog and human adult thyroid. Clin Endocrinol (Oxf) 1989; 31: 655-65.

6. Kmieć Z, Kotlarz G, Smiechowska B, Myśliwski A. The effect of fasting and refeeding on thyroid follicule structure and thyroid hormone levels in young and old rats. Arch Gerontol Geriatr 1998; 26: 161-75.

7. Sekulić M, Sosić-Jurjević B, Filipović B, Milosević V, Nestorović N, Manojlovic-Stojanoski M. The effects of synthetic salmon calcitonin on thyroid $\mathrm{C}$ and follicular cells in adult female rats. Folia Histochem Cytobiol 2005; 43: 103-8.
8. Bocian-Sobkowska J, Malendowicz LK, Woźniak W. Morphometric studies on the development of human thyroid gland in early fetal life. Histol Histopathol 1992; 7: 415-20.

9. Bocian-Sobkowska J, Woźniak W, Malendowicz LK. Morphometric studies on the development of the human thyroid gland. II. The late fetal life. Histol Histopathol 1997; 12: 79-84.

10. Wollman SH, Herveg JP, Tachiwaki O. Histologic changes in tissue components of the hyperplastic thyroid gland during its involution in the rat. Am J Anat 1990; 189: 35-44.

11. Berndorfer U, Wilms H, Herzog V. Multimerization of thyroglobulin (TG) during extracellular storage: isolation of highly cross-linked TG from human thyroids. J Clin Endocrinol Metab 1996; 81: 1918-26.

12. Sivridis E, Giatromanolaki A. The pathogenesis of endometrial carcinomas at menopause: facts and figures. J Clin Pathol 2011; 64: 553-60.

13. Moskalenko R, Romanyuk A, Logvin A. Intrafollicular pressure of colloid thyroid gland determinate the type of folliculogenesis. Georgian Med News 2012; (205): 67-73.

14. Baris $\mathrm{O}$, Savagner F, Nasser V, et al. Transcriptional profiling reveals coordinated up-regulation of oxidative metabolism genes in thyroid oncocytic tumors. J Clin Endocrinol Metab 2004; 89: 994-1005.

15. Nesland JM, Sobrinho-Simões MA, Holm R, Sambade MC, Johannessen JV. Hurthle-cell lesions of the thyroid: a combined study using transmission electron microscopy, scanning electron microscopy, and immunocytochemistry. Ultrastruct Pathol 1985; 8: 269-90. 